\title{
Construct Scheme to Second-period of Headquarters Performance Management System in State Grid
}

\author{
Jian Zhang, Yan Ma, Yan Hou, Dong-wei Lv, Yu-wei Yin \\ China-Power Information Technology Limited Company, Beijing, 100192, China \\ E-mail: zhangjian9@sgepri.sgcc.com.cn; mayan@sgepri.sgcc.com.cn; houyan@sgepri.sgcc.com.cn; \\ lvdongwei@sgepri.sgcc.com.cn; yinyuwei@sgepri.sgcc.com.cn;
}

\begin{abstract}
In order to enhance the performance management informatics level in State Grid Corporation, as well as strength the cohesion between headquarters performance management and authority work tasks, State Grid Corporation launched the second-period construction of headquarters performance management system. The construction scheme of headquarters performance management is the creed document which guides the overall construction direction. In this paper, we will introduce the overall scheme, deployment architecture, application scenario, along with integration scheme with other business systems. At last, a proof of practice on State Grid Corporation headquarters have been performed, whose positive outcome is presented.
\end{abstract}

Keywords-Performance management; Construction scheme; Application Integration

\section{INTRODUCTION}

With the further development of company's strategic, according to the requirement that promote further "Three Centralization Five Huge Two Center"[3], closely combining actual work, headquarters require to further clarify the management responsibilities[1], and associate business procedure[6], regular and standard. Under this background, we need to implement the full-circle procedure management including performance plan, implementation, evaluation, and feedback, as well as build the "Five in One" mechanism, which assembles full duty, procedure, regular, standard and evaluation.

The second-period headquarters performance management system, that is built based on the achievement of the firstperiod construction, in accordance with "SG-ERP" technology architecture, based on SG-UAP technical platform, guided by business requirement, have added work task management and summarize plan management, and realized information management, procedure management, evaluation management, result management and so on. Furthermore it achieves the fullcourse performance management, which effetely promotes the operation of "Five in One" mechanism, and carry forward institutionalize company's strategy target, gradually improving staff and organization performance.

In 2014, the director department of company hold a survey for business management, in order to unify the business management on work task, plan summarize and evaluation management. For the sake of further enhance headquarters performance management, improve headquarters performance business, formulate performance management standard among different departments, the director ministry and information communication ministry jointly organize the construction of the second-period headquarters performance management system.

\section{OVERALL ARCHITECTURE}

\section{A. Business Architecture}

Headquarters performance management business consists of responsibility management, procedure management, task management, evaluation management, result management, selfassessment, and human-resource service platform and so on; the business architecture[2][6] shows as follow.

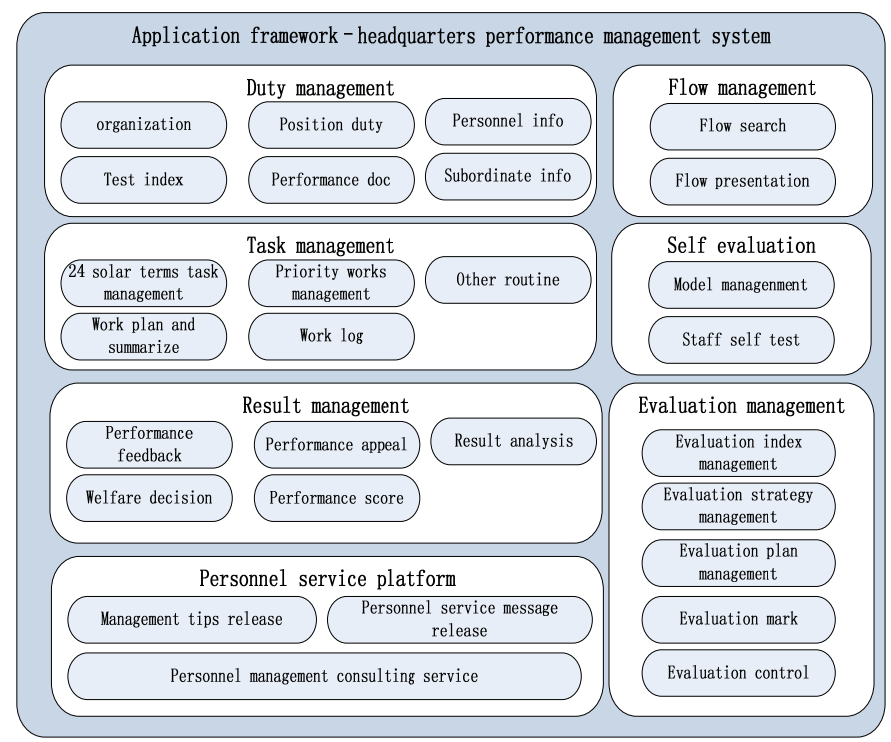

Figure 1 Functional Framework of Second-period of Headquarter performance management system

\section{B. Technical Architecture}

The technical components of State Grid Headquarters performance management system mainly includes presentation layer, application layer, data layer, security service layer, basic service layer, integration layer and running environment, the technical architecture[4][5] shows as follow. 


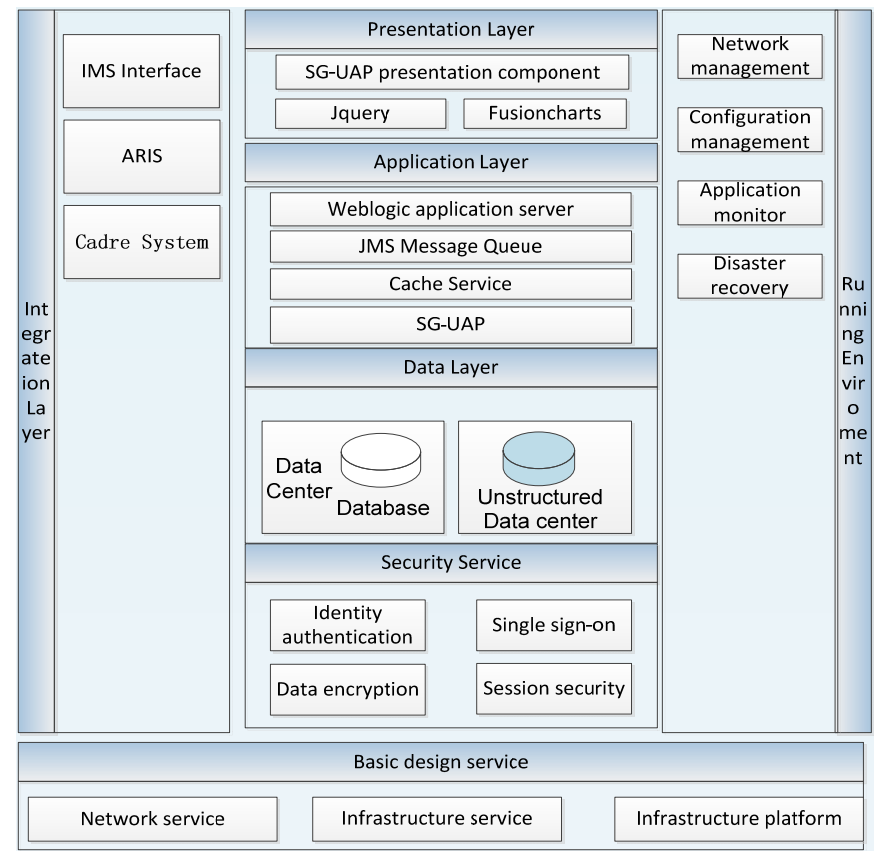

Figure 2 Technical Architecture of the Second-period of Headquarters performance management system.

\section{1 )Presentation layer}

a) SG-UAP presentation component is constructed based on WEB, which user can access it through browser, other software is no need to be installed, and office address is unlimited.

b) JQuery that is a lightweight JavaScript framework, provides massive functions and components, as well as supports various browsers.

c) Fusionchart is a comprehensive JavaScript charting library, which greatly helps achieve stunning animation, rich interactivity and so on.

2) Application Layer

a) SG-UAP : The SG-UAP platform, that is focus on serving for enterprise-level application system development swiftly and reliably, it consists of client component, component system, persistence framework, basic function package, Studio integration development environment and monitor system, in which the component system consists of presentation and business logic component.

b) Weblogic : A JAVA EE scenario based application server, provided by BEA Company, can be used for development, integration, deployment and distributed web application management.

c) JMS message queue: A pool can hold the messages that just are sent and waited for reading, where messages will be sent by order, once the message is read, it will be removed from the queue.

d) Cache: Web caching service is a cache redirection technology by using WEB.

3) Application Layer a) Data center : Provide business data storage.

b) Unstructured data center : Store unstructured file by unstructured system.

4) Security Service Layer

a) Identity authentication : Apply the identity authentication component in unified authority management platform.

b) Single sign-on authentication: Apply the unified authentication approach provided by the Unified Authentication Management Platform, which can integrate with portal seamlessly.

c) Data encryption: A component, that is purely indigenous, can encrypt the core business data and user data.

d) Session security protection: Apply the session security component provided by the Unified Authentication Management Platform.

5) Integration Layer

a) IMS interface : Realize integration with IMS, to monitor system running situation.

b) ARIS interface : Realize integration with ARIS(procedure management platform), to present business procedure.

c) Cadre interface: Realize the presentation of cadre information.

6) Basic design service and running environment

based on disaster recovery center in State Grid Corporation, to achieve security assurance.

\section{Data Architecture}

For the sake of realizing the integration of headquarters performance management information, unifying various data source, enhancing analysis and searching function, achieving multiple format outcome, as well as satisfying various management requirement, we need to make standard management procedure, strength the supervision for headquarters performance work, and improve search and analysis function. Based on the first-period construction of headquarters performance management system, in accordance with headquarter performance management work procedure, combining priorities work; we work out the data architecture[7] as figure 3 shows. 


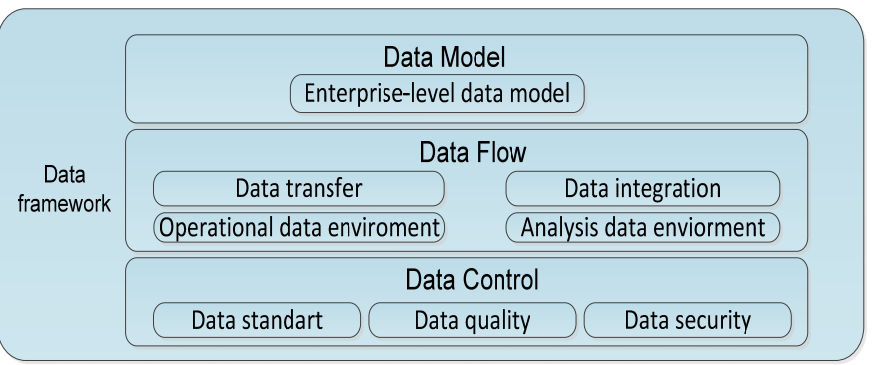

Unity: Design unified data view among various business, and Realize unified data transfer model; Design unified data control strategy according to management level among various business; make unified data control strategy among timing, un-timing, structured, unstructured data.

Standard: Refer to mature and scientific data framework standard from international electric company, to design data model, data distribute and data control system, to realize data standard with State Grid characteristics.

Extensibility: realize data framework modeling and hierarchical, to support the extensibility of core data

Figure 3 Data Framework of Second-period of Based performance management system

\section{Security Architecture}

We store headquarters staff work task data, summary and plan data, evaluation procedure and result data, thus the security requirement for system data is relatively high. Under this requirement, we need to take encryption measures on client browser, data storage and document storage. Therefore, we make the design of security framework, from the aspect of network security, operation system security, application security, data security and physical host security. The overall security shows as figure 4 .
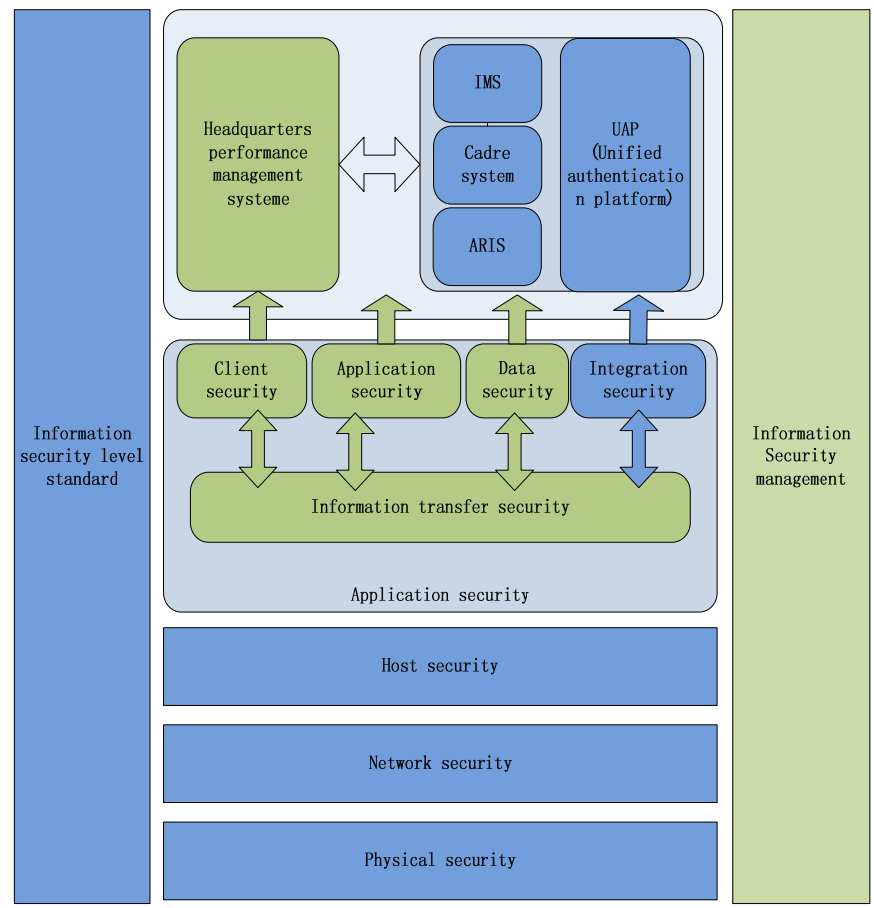

Figure 4 Security Framework of Second-period of Based performance management system

\section{DEPLOYEMENT SCHEME}

The deployment framework of second-period construction of the headquarters performance management system follows the first-period framework, figure 5 shows the detail.

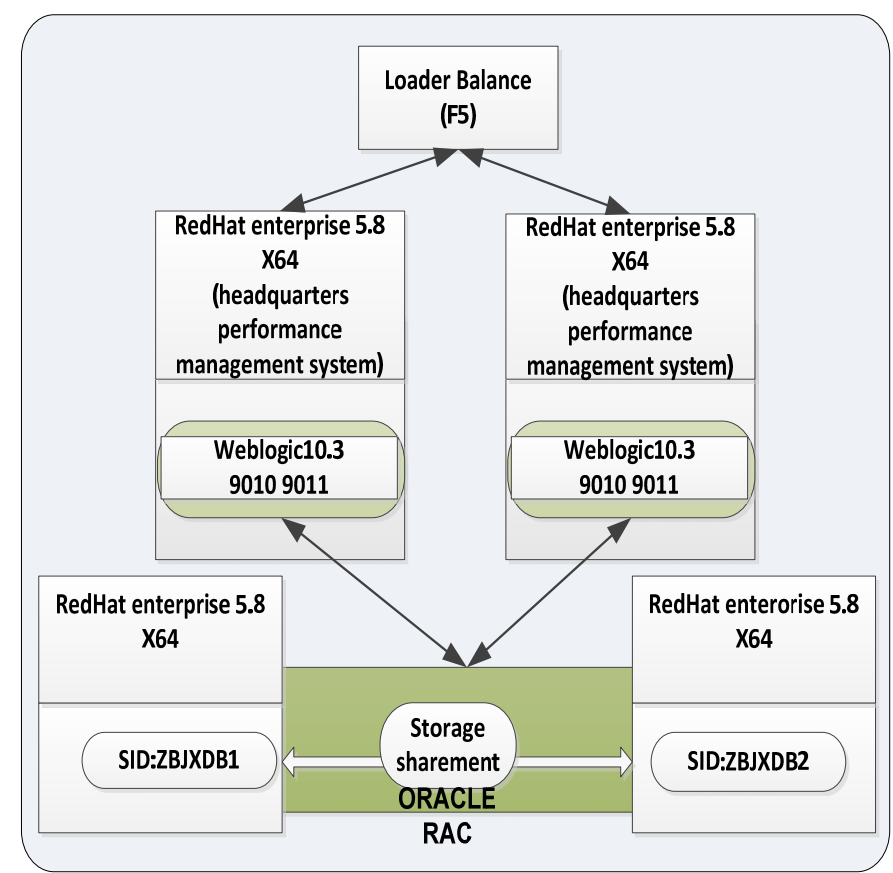

Figure 5 Deploy Framework of State Grid Headquarters

\section{INTEGRATION SCHEME}

\section{A. UAP integration scheme}

The template is designed so that author affiliations are not repeated each time for multiple authors of the same affiliation. Please keep your affiliations as succinct as possible (for example, do not differentiate among departments of the same organization). This template was designed for two affiliations.

\section{B. Portal integration scheme}

Based on the integration with UAP, headquarters performance management system is integrated with portal automatically, as access link and login icon is required.

\section{IMS integration scheme}

Headquarters performance management system is integrated with IMS(Integration Monitor System), using WebService to provide data interface with business index and user data, extracted data through IMS at regular time.

\section{ARIS integration scheme}

By the means of page integration, present business procedure information in ARIS.

\section{E. Cadre system integration scheme}

Via the approach of page integration, present cadre staff personal information, including age, working-age, education experience, curriculum vitae and so on. 


\section{CONCLUSIONS}

Guided by this scheme, we have launched the secondperiod construction of headquarters performance information system on April 2014, and have made some achievements. We have finished the development of deputy management, work task management; summary plan management, evaluation management, result management; self-evaluation and personnel service and so on, as well as relatively testing work, and finally finished the deployment on Dec 2014. Through the practice of application, we can draw the conclusion that the second-period construction scheme is doable and reasonable.

\section{REFERENCES}

[1] State Grid Corporation headquarters staff performance evaluation layout.

[2] Notice on the issuance of the " 24 solar term" in State Grid Corporation work layout.

[3] State Grid Company "the Twelve-Five” informatic development layout.

[4] State Grid Company informatics SG-ERP architecture design layout.

[5] State Grid Company pulic data model SG-CIM design.

[6] State Grid Company headquarters performance management system user requirement specification.

[7] State Grid Company unstructured data management platform typical design. 